\title{
KONSENTRASI SEDIMEN SUSPENSI RATA-RATA KEDALAMAN PADA SALURAN MENIKUNG BERDASARKAN HASIL PENGUKURAN DAN ANALISIS
}

\author{
Chairul Muharis \\ Dosen Jurusan Teknik Sipil Politeknik Negeri Padang \\ Email : ch_muharis@yahoo.com
}

\begin{abstract}
ABSTRAK : Akibat adanya gaya sentrifugal di tikungan saluran maka kecepatan aliran arah transversal akan meningkat di outer bank. Fenomena ini tentu akan mempengaruhi distribusi konsentrasi sedimen suspensi rata-rata kedalaman. Perubahan distribusi konsentrasi sedimen suspensi hanya akan dapat diketahui dengan melakukan pengukuran secara langsung pada aliran menikung di lapangan atau di laboratorium. Tujuan penelitian ini adalah untuk mengetahui profil distribusi konsentrasi sedimen suspensi dari pengukuran di lapangan, kemudian dibandingkan dengan profil distribusi konsentrasi sedimen suspensi prediksi berdasarkan persamaan Rouse. Penelitian dilakukan di Saluran Irigasi Mataram Yogyakarta. Hasil penelitian menunjukkan bahwa akibat perubahan kecepatan aliran di tikungan maka konsentrasi sedimen suspensi rata-rata kedalaman juga mengalami perubahan. Secara umum konsentrasi sedimen suspensi rata-rata tampang ke arah sisi luar tikungan mengalami pengurangan dan sebaliknya ke arah sisi dalam tikungan semakin meningkat. Konsentrasi sedimen suspensi rata-rata tampang dapat diwakili berdasarkan pengambilan sampelnya pada jarak $R=0,46 B$ atau 0,46 lebar saluran diukur dari inner bank.
\end{abstract}

Kata kunci: Konsentrasi, Sedimen suspensi dan, Arah transversal.

\begin{abstract}
The centrifugal force at bend channel flow will increase in the outer bank. This phenomenon would affect to depth-averaged suspended sediment concentration. Suspended sediment concentration value will be known by conducting research directly on the bend channel the flow in the field or in laboratory. The purpose of this research was to determine the distribution of suspended sediment concentration profile based on field data and then compared to distribution of suspended sediment concentration profile of predictions by Rouse equation. The research was conducted in Irrigation Mataram Yogyakarta. The results showed that the change of velocity in the outer bank and can also change the depth-averaged suspended sediment concentration. The suspended sediment concentration have increased in the outer bank, but decreased in the inner bank. The cross section average suspended sediment concentration can easily be represented by the sample collection at a distance $R=0.46 \mathrm{~B}$ or 0.46 of channel width and so measured from the inner bank.
\end{abstract}

Keywords: concentration, suspended sediment and, transverse direction.

Informasi tentang angkutan sedimen seringkali sangat dibutuhkan pada pekerjaan-pekerjaan keteknikan dari berbagai aspek teknik hidro, seperti pada pekerjaan perancangan bangunan pengendalian sungai, pengendalian banjir, perencanaan saluran stabil, dan berbagai bangunan bangunan sungai lainnya. Salah satu parameter aliran yang sering dikaitkan dengan proses angkutan sedimen adalah distribusi konsentrasi sedimen suspensi. Dengan diketahuinya distribusi konsentrasi sedimen suspensi pada suatu sungai, fenomena angkutan sedimen seperti misalnya awal gerak 
sedimen, proses erosi, pengendapan sedimen, dan lain-lain, akan lebih dapat dipahami.

Penelitian-penelitian sebelumnya banyak membahas mengenai aliran sedimen suspensi yang dilakukan pada saluran terbuka yang lurus, terutama hubungan antara konsentrasi sedimen suspensi dan profil kecepatannya. Penelitian tersebut di antaranya adalah Coleman (1981) melakukan penelitian mengenai pengaruh sedimen suspensi terhadap distribusi kecepatan pada saluran terbuka, dan melaporkan bahwa ketebalan lapisan logaritmik dari profil kecepatan menurun ketika konsentrasi sedimen suspensi ditingkatkan.

Kironoto (2004, 2007, 2009) melaporkan bahwa ada korelasi antara lokasi pengukuran dan pengambilan sampel dengan konsentrasi sedimen suspensi rata-rata tampang. Berangkat dari latar belakang hasil penelitian terdahulu yang hanya dilakukan pada saluran lurus, maka pada penelitian ini akan dilakukan pada saluran menikung.

\section{LANDASAN TEORI}

\section{a. Distribusi kecepatan}

Pada saluran terbuka, nilai distribusi kecepatan aliran sering dibedakan pada daerah inner region dan daerah outer region. Daerah inner region adalah daerah dekat dasar, dimana distribusi kecepatan logaritmik masih berlaku, sedangkan daerah outer region adalah daerah yang jauh dari dasar, dimana profil kecepatan menyimpang secara jelas dan sistematik dari hukum distribusi kecepatan logaritmik. Distribusi kecepatan di daerah inner region, yang dibatasi oleh $y / \delta<0.2$ dapat dirumuskan dengan persamaan (Yang, 1996):

$$
\frac{u}{u_{*}}=\frac{1}{\kappa} \ln \left(\frac{y}{k_{S}}\right)+B r
$$

Di mana $u$ adalah kecepatan rata-rata titik pada jarak $y$ dari titik referensi; $u_{*}$, kecepatan geser; $\kappa$, konstanta universal Von-Karman $(\kappa=0.4)$; $\mathrm{Br}$, konstanta integrasi dari persamaan distribusi kecepatan logaritmik, dan $k_{S}$ adalah kekasaran dasar equivalen dari Nikuradse.

\section{b. Distribusi konsentrasi sedimen}

Distribusi konsentrasi sedimen dapat dihitung dengan konsep difusi untuk sedimen suspensi, $\varepsilon_{s}$. Pada aliran dengan kondisi seragam permanen akan terjadi keseimbangan antara butiran sedimen yang bergerak ke bawah dipengaruhi gravitasi dan difusi ke atas yang digabungkan dengan fluktuasi turbulen. Garde dan Ranga Raju (1977) memberikan persamaan difusi yang digunakan untuk menghitung distribusi material suspensi arah vertikal, yaitu:

$$
w_{s} C+\varepsilon_{s} \frac{\partial C}{\partial y}=0
$$

$C$ konsentrasi sedimen suspensi rata-rata pada kedalaman $y$ dari titik referensi, $w_{s}$ kecepatan jatuh partikel , $\varepsilon_{s}$, koefisien diffusi.

\section{c. Prediksi distribusi konsentrasi sedimen suspensi}

Distribusi konsentrasi sedimen suspensi dapat diprediksi dengan beberapa persamaan, diantaranya adalah persamaan Rouse dalam Graf (1984) yang dikembangkan untuk aliran seragam. Berdasarkan hasil penelitian yang dilakukan Kironoto (2007) penggunaan persamaan Rouse menberikan hasil cukup baik terutama untuk pengukuran ditengah saluran Persamaan (3) didasarkan pada distribusi kecepatan logaritmik dan asumsi bahwa koefisien difusi sedimen mempunyai nilai yang sama dengan koefisien transfer momentum, dan dapat dituliskan sebagai berikut:

$$
\frac{C}{C_{a}}=\left(\frac{D-y}{y} \frac{a}{D-a}\right)^{Z}
$$

Dalam hal ini $C$ adalah konsentrasi sedimen suspensi pada suatu titik berjarak $y$ dari titik referensi; $C_{a}$, konsentrasi referensi yang berjarak $a$ dari titik referensi; $D$, kedalaman aliran, dan $Z$ adalah parameter Rouse.

$$
z=\frac{w_{s}}{\kappa \cdot u_{*}}
$$

Di mana $w s$, kecepatan endap partikel suspensi; $\boldsymbol{u}_{*}$, kecepatan gesek, dan $\kappa$ konstanta von-Karman (merupakan parameter distribusi kecepatan)

\section{c. Kecepatan endap partikel sedimen suspensi}

Kecepatan endap sedimen suspensi dapat dihitung dengan persamaan Rouse:

$$
w_{s}=\frac{1}{18} \frac{\gamma_{s}-\gamma}{\gamma} g \frac{d_{s}^{2}}{v}
$$


Di mana $d_{s}$, diameter partikel suspensi representatif, $w_{s}$, kecepatan endap partikel sedimen suspensi, $\gamma_{s}$ dan $\gamma$ berat jenis sedimen dan air, $v$ viskositas kinematik dan $g$ percepatan gravitasi.

\section{METODOLOGI PENELITIAN}

Metode yang diterapkan pada penelitian ini adalah eksperimen lapangan, yakni seluruh kegiatan pengukuran maupun pengambilan data dilaksanakan di lapangan. Lokasi penelitian di laksanakan pada 5 (lima) titik saluran irigasi Mataram. Titik-titik pengukuran kecepatan dan pengambilan sampel sedimen suspensi untuk setiap saluran menikung ditetapkan pada 5 (lima) cross section berada dalam busur saluran menikung (1, 2, 3, 4 dan 5), seperti terlihat pada Gambar 1:

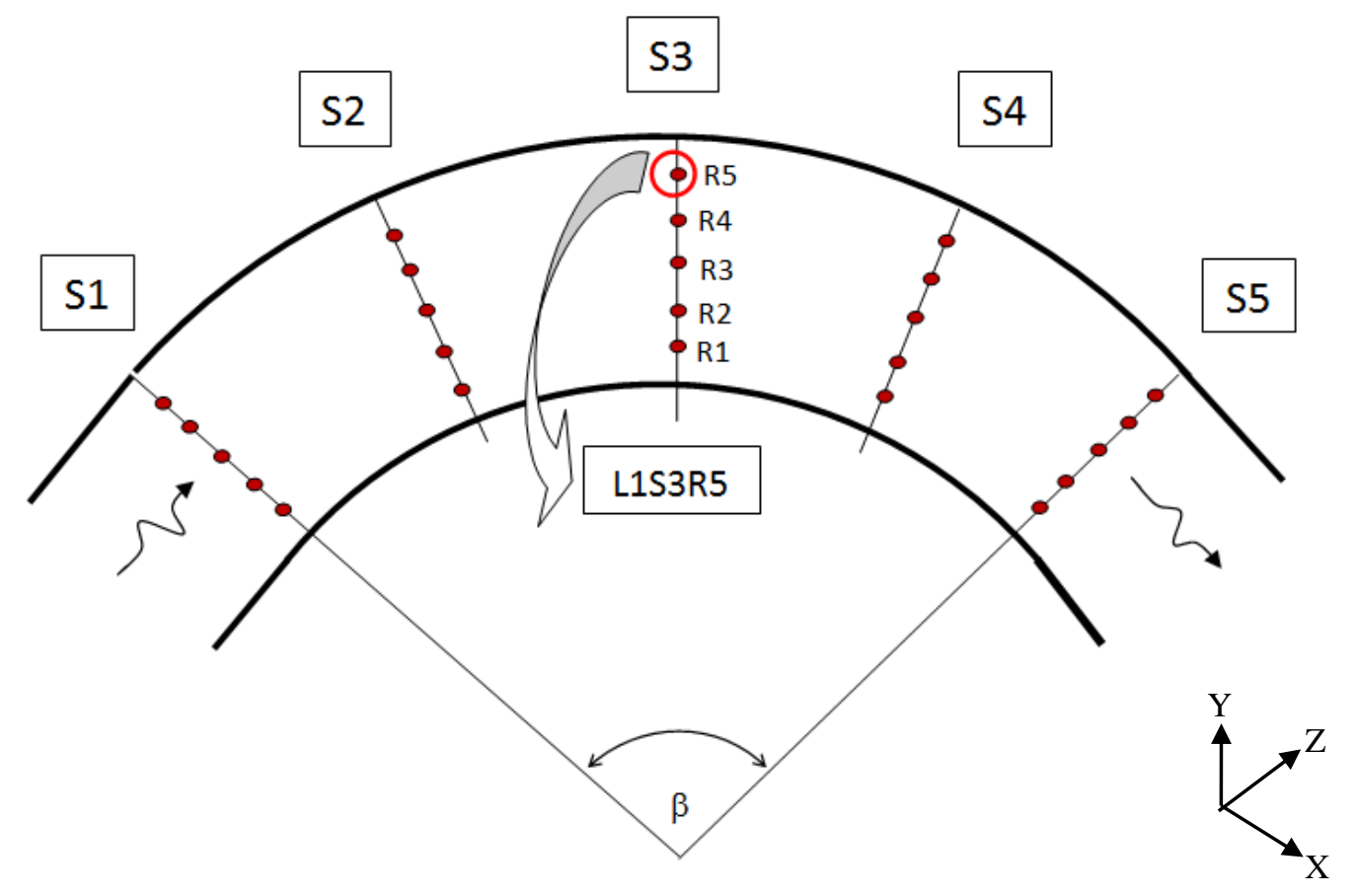

Gambar 1. Sketsa Pengukuran Cross Sections Lokasi1.

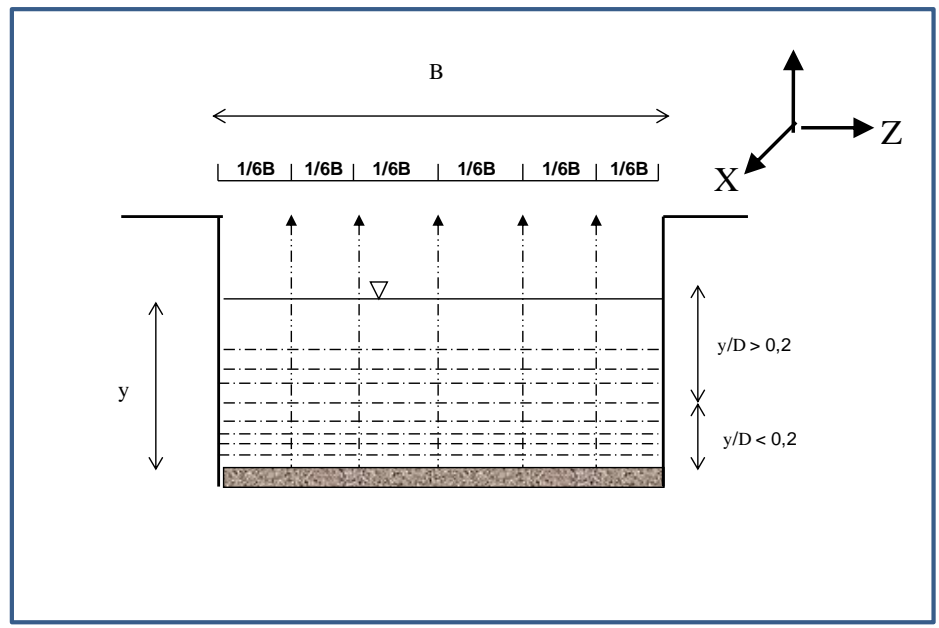

Gambar 2. Titik-titik pengukuran arah transversal dan vertikal

Pada masing-masing cross section dibagi sebanyak 5 (lima) titik arah transversal atau tegak lurus arah aliran, seperti terlihat pada Gambar 2.
Setiap lima titik tersebut dibagi lagi untuk beberapa titik kedalaman untuk jumlah yang relatif cukup. Titik-titik tersebut adalah pada $y / D \leq 0,2$ untuk data di dekat dasar (inner 
region,), dan $\mathrm{y} / D \geq 0,2$ untuk data di outer region. Selanjutnya setiap data yang diperoleh diberi notasi agar memudahkan dalam mengidentifikasnya. Jumlah titik-titik pengukuran dan pengambilan sampel pada kedalaman vertikal sewaktu waktu bisa berkurang atau bertambah sesuai situasi dan kondisi lapangan pada saat itu.

Selama pelaksanaan pengukuran di lapangan ketinggian muka air perlu selalu dikontrol, yakni dengan cara menempatkan peil schaal dikedua sisi penampang saluran, kemudian diberi tanda. Selanjutnya setiap perubahan ketinggian muka air dicatat dengan seksama. Hal ini dilakukan karena perubahan tinggi muka air akan berpengaruh terhadap besarnya debit aliran dan nilai aspek rasio dari penampang saluran tersebut.

Tabel 1. Variabel pengukuran dan hitungan aliran menikung

\begin{tabular}{cccccccccc} 
RUN & $\begin{array}{c}Q \\
(\mathrm{~m} 3 / \mathrm{dt})\end{array}$ & $\begin{array}{c}D \\
(\mathrm{~m})\end{array}$ & $B / D$ & $\begin{array}{c}w_{S} \\
(\mathrm{~cm} / \mathrm{dt})\end{array}$ & $\begin{array}{c}\bar{U} \\
(\mathrm{~m} / \mathrm{dt})\end{array}$ & $\begin{array}{c}\bar{C} \\
(\mathrm{gr} / \mathrm{lt})\end{array}$ & $\begin{array}{c}\text { Fr } \\
u_{*} \\
(\mathrm{~m} / \mathrm{dt})\end{array}$ & $\begin{array}{c}\bar{C}_{Y} \\
(\mathrm{gr} / \mathrm{lt})\end{array}$ \\
\hline L1SIR1 & & 0,72 & 5,86 & $1,64 \times 10^{-3}$ & & & 0,219 & 0,075 & 6,393 \\
L1SIR2 & & 0,73 & 5,78 & $1,64 \times 10^{-3}$ & & & 0,218 & 0,119 & 6,204 \\
L1SIR3 & 1,817 & 0,75 & 5,63 & $1,64 \times 10^{-3}$ & 0,582 & 6,066 & 0,215 & 0,148 & 5,961 \\
L1SIR4 & & 0,77 & 5,48 & $1,64 \times 10^{-3}$ & & & 0,212 & 0,131 & 5,923 \\
L1SIR5 & & 0,78 & 5,41 & $1,64 \times 10^{-3}$ & & & 0,211 & 0,144 & 5,850 \\
\hline L1S2R1 & & 0,75 & 5,63 & $1,64 \times 10^{-3}$ & & & 0,215 & 0,140 & 6,273 \\
L1S2R2 & & 0,76 & 5,55 & $1,64 \times 10^{-3}$ & & & 0,213 & 0,163 & 6,109 \\
L1S2R3 & 1,927 & 0,80 & 5,25 & $1,64 \times 10^{-3}$ & 0,579 & 5,957 & 0,207 & 0,183 & 5,879 \\
L1S2R4 & & 0,85 & 4,94 & $1,64 \times 10^{-3}$ & & & 0,201 & 0,188 & 5,807 \\
L1S2R5 & & 0,85 & 4,94 & $1,64 \times 10^{-3}$ & & & 0,201 & 0,185 & 5,719 \\
\hline L1S3R1 & & 0,70 & 6,00 & $1,64 \times 10^{-3}$ & & & 0,214 & 0,117 & 6,172 \\
L1S3R2 & & 0,78 & 5,38 & $1,64 \times 10^{-3}$ & & & 0,203 & 0,107 & 5,998 \\
L1S3R3 & 1,850 & 0,80 & 5,25 & $1,64 \times 10^{-3}$ & 0,561 & 5,877 & 0,200 & 0,123 & 5,818 \\
L1S3R4 & & 0,83 & 5,06 & $1,64 \times 10^{-3}$ & & & 0,197 & 0,117 & 5,756 \\
L1S3R5 & & 0,85 & 4,94 & $1,64 \times 10^{-3}$ & & & 0,194 & 0,106 & 5,643 \\
\hline L1S4R1 & & 0,64 & 6,56 & $1,64 \times 10^{-3}$ & & & 0,215 & 0,131 & 6,040 \\
L1S4R2 & & 0,73 & 5,75 & $1,64 \times 10^{-3}$ & & & 0,201 & 0,135 & 5,903 \\
L1S4R3 & 1,716 & 0,77 & 5,45 & $1,64 \times 10^{-3}$ & 0,537 & 5,769 & 0,196 & 0,132 & 5,718 \\
L1S4R4 & & 0,82 & 5,12 & $1,64 \times 10^{-3}$ & & & 0,190 & 0,136 & 5,667 \\
L1S4R5 & & 0,84 & 5,00 & $1,64 \times 10^{-3}$ & & & 0,187 & 0,146 & 5,518 \\
\hline L1S5R1 & & 0,65 & 6,46 & $1,64 \times 10^{-3}$ & & & 0,217 & 0,081 & 5,870 \\
L1S5R2 & & 0,70 & 6,00 & $1,64 \times 10^{-3}$ & & & 0,209 & 0,085 & 5,784 \\
L1S5R3 & 1,723 & 0,75 & 5,60 & $1,64 \times 10^{-3}$ & 0,548 & 5,638 & 0,202 & 0,117 & 5,608 \\
L1S5R4 & & 0,80 & 5,25 & $1,64 \times 10^{-3}$ & & & 0,196 & 0,101 & 5,538 \\
L1S5R5 & & 0,84 & 5,00 & $1,64 \times 10^{-3}$ & & & 0,191 & 0,108 & 5,389 \\
\hline
\end{tabular}

Keterangan:

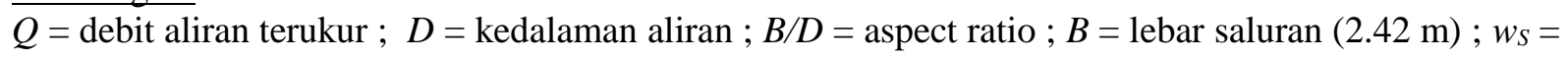
kecepatan endap $; \bar{U}=$ kecepatan rata-rata tampang $; u_{*}=$ kecepatan gesek $; \bar{C}=$ konsentrasi ratarata tampang (transversal); $F r=U /(g D)^{0.5} ; \bar{C}_{Y}=$ konsentrasi rata-rata kedalaman aliran. 


\section{DATA UNTUK ANALISIS}

Data pengukuran diberi notasi/kode $\mathrm{L}, \mathrm{S}$ dan $\mathrm{R}$, yang merupakan singkatan dari $\mathrm{L}=$ location, $\mathrm{S}=$ cross section, dan $\mathrm{R}=$ radius (titik arah transversal), Notasi itu diikuti dengan angkaangka yang menginformasikan urutan lokasi penelitian, potongan melintang dari hulu ke hilir saluran dan posisi pengukuran arah transversal dari inner bank ke outer bank. Misalnya, nama kode data pengukuran L1S3R1 yang mempunyai makna bahwa data pengukuran diperoleh di lokasi pertama, pada cross section ke tiga atau di tengah tikungan, dan pada posisi pertama dari outer bank ke inner bank atau posisi pertama arah transversal. Berdasarkan data hasil pengukuran kecepatan dan pengukuran konsentrasi sedimen suspensi setelah dianalisa dibagi dalam lima kelompok yakni untuk penampang masuk dan keluar tikungan terdapat dua dan di dalam tikungan terdapat tiga, pengukuran seperti diskripsi pada tabel 1 .

\section{HASIL DAN PEMBAHASAN}

Pada bagian hasil dan pembahasan ini akan dibahas masing-masing dari sesi hasil pengukuran di lapangan. Sebagai contoh pada Gambar 3 berikut ini menunjukkan hasil pengukuran sesi 1 , yakni sesi diawal masuk tikungan.

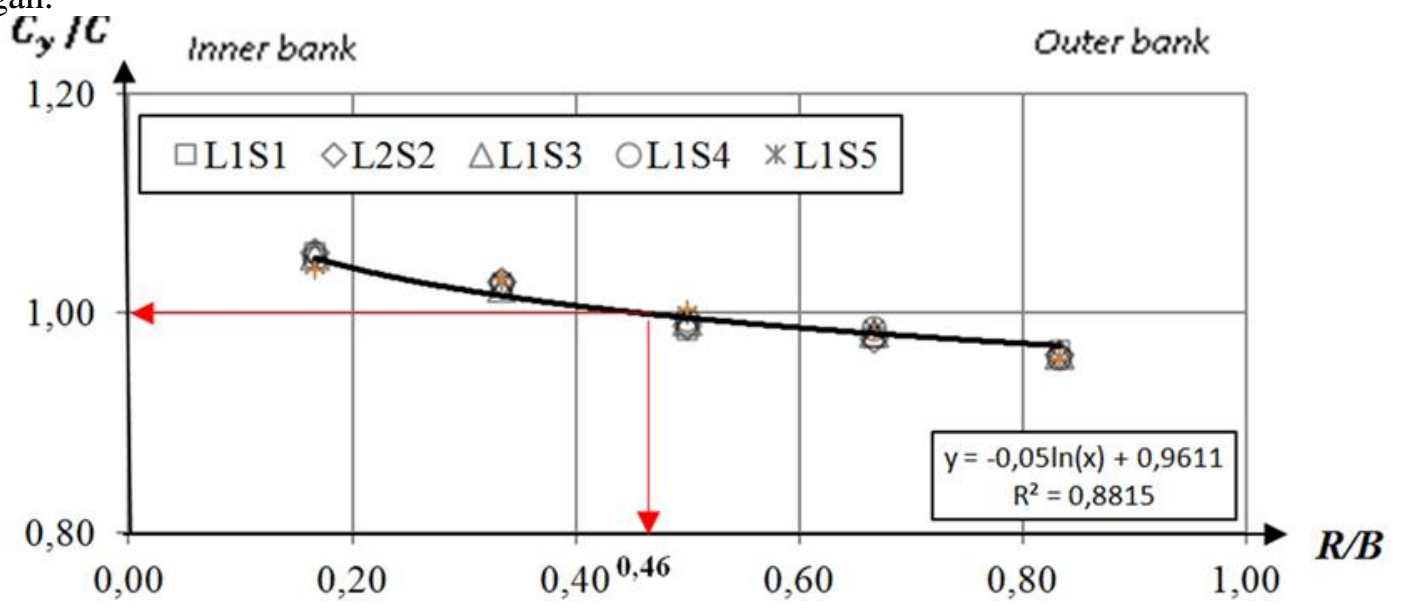

Gambar 4. Konsentrasi sedimen suspensi arah transversal untuk lokasi1

Gambar 4, menunjukkan trend distribusi konsentrasi sedimen suspensi $\bar{C}$ arah transversal. Pada Gambar 4 terlihat trend nilai konsentrasi sedimen suspensi untuk arah transversal adalah cenderung mengecil dari inner bank ke outer bank.
Hasil pengukuran konsentrasi sedimen suspensi secara umum di lokasi pengukuran 1 (satu) menunjukkan nilai konsentrasi yang sesuai dengan persamaan transpor konveksi diffusi. Pada lokasi 1 menunjukkan bahwa nilai konsentrasi sedimen suspensi maksimum terjadi di dekat dasar dan semakin berkurang sampai di permukaan aliran.

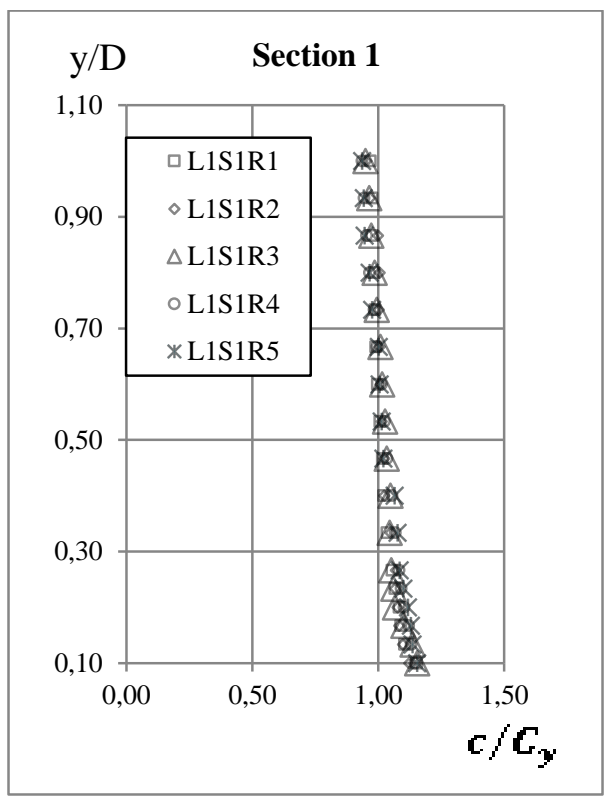

Gambar 3. Distribusi konsentrasi pada saluran menikung 
meningkat maka akan menurunkan konsentrasi sedimen suspensi pada aliran.

Hasil regressi menunjukan nilai $\bar{C}_{y} / \bar{C}=1$ berada pada posisi $0,46 R / B$, nilai ini bermakna bahwa konsentrasi sedimen suspensi rata-rata tampang dapat diwakili pengambilan sampelnya pada jarak $R=0,46 B$ atau 0,46 lebar saluran yang diukur dari inner bank.
Hasil pengukuran konsentrasi arah transversal di lapangan dan hasil prediksi menggunakan persamaan Rouse maka diperoleh perbandingan profil distribusi konsentrasi sedimen suspensi kedua. Hasil pengukuran tersebut dapat dilihat pada Gambar 5 berikut ini:
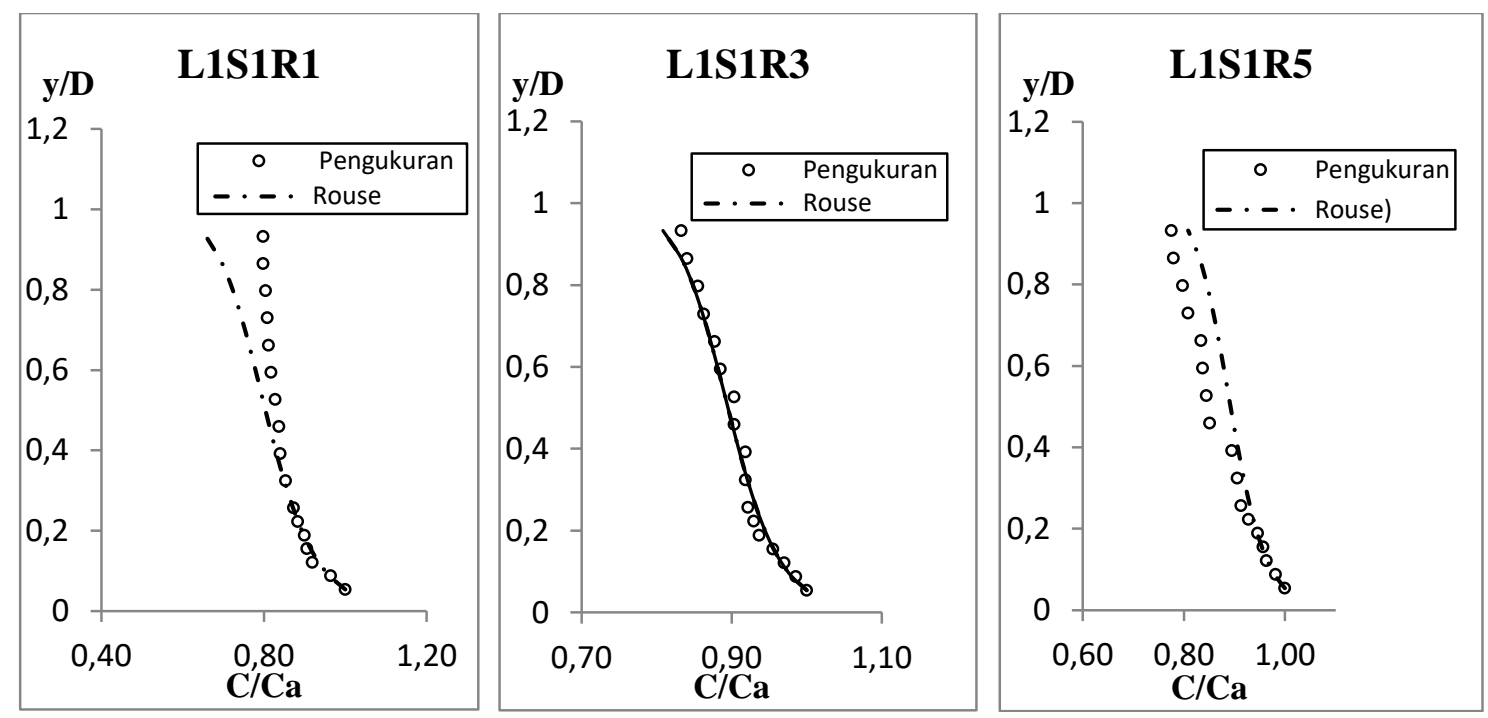

Gambar 5. Perbandingan distribusi konsentrasi hasil pengukuran dan Rouse

Hasil pengujian konsentrasi sedimen suspensi rata-rata kedalaman pada saluran menikung menunjukkan bahwa profil distribusi konsentrasi sedimen pada lokasi inner bank lebih besar dari pada hasil pengujian Rouse, sedangkan pada lokasi outer bank lebih kecil dari pada hasil pengujian Rouse. Hasil pengujian ini memberikan bukti adanya perbedaan antara profil distribusi konsentrasi sedimen suspensi hasil pengukuran langsung di lapangan dengan profil distribusi konsentrasi sedimen suspensi hasil prediksi menggunakan persamaan Rouse pada lokasi inner bank dan outer bank.

Lebih lanjut hasil pengujian menunjukkan bahwa pada posisi tengah saluran dan arah transversal sebelum masuk tikungan, nilai distribusi konsentrasi sedimen suspensi hasil pengukuran mendekati sama dengan distribusi konsentrasi sedimen suspensi hasil prediksi menggunakan persamaan Rouse. Hasil analisis memperlihatkan bahwa persamaan Rouse masih dapat berlaku dengan baik atau masih valid untuk posisi di tengah saluran pada awal tikungan atau sesi 1 , sedangkan untuk posisi yang lain tidak berlaku lagi karena aliran sudah banyak mengalami perubahan.

\section{KESIMPULAN}

1. Konsentrasi sedimen suspensi secara umum di semua lokasi pengukuran menunjukkan nilai masih mengikuti persamaan transpor konveksi diffusi dengan nilai konsentrasi sedimen suspensi maksimum terjadi di dekat dasar dan semakin berkurang sampai permukaan aliran.

2. Trend nilai konsentrasi sedimen suspensi rata-rata tampang untuk arah transversal, nilainya mengalami penurunan dari inner bank ke arah outer bank. Pengukuran atau pengambilan sampel konsentrasi sedimen suspensi berjarak 0,36 $B$ dari inner bank, hasilnya dapat mewakili konsentrasi sedimen suspensi rata-rata tampang.

3. Persamaan Rouse masih dapat berlaku dengan baik atau masih valid untuk posisi di tengah saluran sedangkan untuk posisi yang lain tidak berlaku lagi karena aliran sudah banyak mengalami perubahan. 


\section{UCAPAN TERIMAKASIH}

Ucapan terima kasih disampaikan kepada Balai Sungai Serayu-Opak yang memberi ijin melakukan penelitian di Saluran Irigasi Mataram, Lembaga Penelitian dan Pengabdian Kepada Masyarakat (LPPM) Universitas Gadjah Mada, yang telah memberikan support dana penelitian Pascasarjana Tahun Anggaran 2012, selanjutnya kepada rekan mahasiswa S2 Teknik Sipil banyak membantu sehingga tulisan ini dapat terwujud.

\section{DAFTAR PUSTAKA}

Coleman, N. L., 1981, Velocity Profiles With Suspended Sediment., J. Hydr. Res., 19(3), 211-229.

Graf, W.H., 1984, Hydraulics of Sediment Transport, McGraw-Hill Book Company, New York.

Kironoto, B.A., Andoyono, T., Yustiana, F, dan Muharis, C., 2004, "Kajian Metode Pengambilan Sampel Sedimen Suspensi Sebagai Dasar Penentuan Debit Sedimen Pada Saluran Terbuka", Penelitian Hibah
Bersaing XII/1-Th. Anggaran 2004, Lembaga Penelitian, Universitas Gadjah Mada, Yogyakarta.

Kironoto, B.A., Totoh Andoyono, Fransiska Yustiana dan Chairul Muharis., 2007, "Karakteristik Aliran Tidak Seragam dengan Sedimen Suspensi pada Saluran Terbuka”, Dinamika TEKNIK SIPIL, Volume 7, Nomor 2, Juli 2007 : 154 - 162 Universitas Gadjah Mada, Yogyakarta.

Kironoto, B.A, Yulistiyanto, B., 2009, "The Validity of Rouse Equation For Predicting Suspended Sediment Concentration Profiles in Transversal Direction of Uniform Open Channel Flow", International Conference on Sustainable Development for Water and Waste Water Treatment, Yogyakarta.

Yang, C T, 1996, Sediment Transport Theory and Practice, The McGraw-Hill Companies, Inc., New York. 